аспирант социологического факультета Московского государственного университета имени М.В. Ломоносова

\section{ОБРАЗОВАНИЕ КАК ИНСТРУМЕНТ СОЦИОКУЛЬТУРНОЙ ДИФФЕРЕНЦИАЦИИ В ТРУДАХ БЭЗИЛА БЕРНСТЕЙНА}

\section{Аннотация:}

Статья посвящена актуальной проблеме неравенства в образовании, складывающегося на основе культурных различий между детьми. Принято считать, что современное общество предоставляет все возможности для детей из разных слоев получить равный доступ к образованию. Вместе с тем существуют исследования, которые показывают изначальные препятствия в деле демократизации образования. Одно из них принадлежит британскому исследователю Бэзилу Бернстейну, который выявил существование так называемых «культурных кодов», т. е. специфических грамматических конструкций и стиля мышления, объединяющего представителей групп разного уровня дохода и различного происхождения. Выявлено, что к детям с равным IQ, но из разных социальных слоев учителя относятся по-разному, в первую очередь из-за их неодинакового способа выражения мыслей. Более того, детям из низшего класса сложно воспринимать речь учителей и детей из более высоких классов. Все это приводит к низкой успеваемости обучающихся из низиих классов, а также к их маркировке как «несообразительных». Подобные последствия обусловливает и смешение в одном классе выходцев из разных этнических общностей, что показано на примерах мексиканских детей, а также детей коренного населения Дальнего Востока России. Система образования не испытывала на себе коренных преобразований еще с начала века. В настоящее время она не учитывает всех социокультурных изменений, проходящих в контексте глобализации и демократизации общества. Поэтому автор обосновывает тезис о необходимости пересмотра текущей организации учебного процесса в школах.

\section{Ключевые слова:}

неравенство в образовании, система образования, Бэзил Бернстейн, социокультурная дифференциация в образовании, социокультурные отличия, конфликтологический подход в социологии образования, школьное образование, демократизация образования, глобализация.

\author{
PhD student, \\ Sociology Department, \\ Lomonosov Moscow State University

\section{EDUCATION AS A TOOL OF SOCIAL AND CULTURAL DIFFERENTIATION IN WORKS OF BASIL BERNSTEIN}

The paper analyzes the current issue of inequality in education because of the cultural differences in children. Modern society is considered providing equal access to education for children of different social groups. However, several studies show the initial obstacles to the democratization of education. One of them belongs to British researcher Basil Bernstein. He discovered the so-called "cultural codes", i.e. the specific grammatical constructions and the ways of thinking, which bring together the representatives of groups with different levels of income and backgrounds. Children with equal IQ of different social strata are perceived by the teachers not in the same way primarily because of the irregular way of expressing their ideas. More than that, it is difficult for children of the low stratum to perceive the speech of teachers and children of the high stratum. That leads to poor academic progress of children of the low stratum and labelling them as "not smart". Ethnic mix in one class leads to quite the same consequences exemplified by Mexican children and indigenous children of the Russian Far East. The education system has not been radically changed since the beginning of the century. At present, it does not consider all social and cultural changes in the context of the world globalization and the democratization of society. Therefore, the author proves the need to revise the current situation in the delivery of school education.

Образование традиционно считается одним из базовых социальных институтов, оно ответственно за культурную трансмиссию и подготовку новых членов общества, сохраняя, таким образом, стабильность существующей социальной системы. Образование также выступает одним из основных социальных лифтов, поскольку именно обладание информацией и способность применять знания служат условиями для перемещений в социальном поле информационного общества. Данная модель социальной мобильности более демократична, так как, во-первых, в современном мире большая часть информации находится в свободном доступе, а потому каждый имеет равное количество шансов, чтобы набрать необходимый культурный капитал; во-вторых, социальное положение индивида обусловлено исключительно качеством и количеством имеющихся знаний, а не происхождением, расой или другими аскриптивными признаками. Другими словами, образование 
в современном обществе, по мысли некоторых ученых-футурологов, приближает расцвет новой системы социальной стратификации - меритократии - такого общественного устройства, где социальный статус определяется исключительно трудолюбием человека, его знаниями и способностью их применять [1, р. 30]. Впоследствии термин, введенный английским социологом М. Янгом, был использован Д. Беллом [2] как синоним «постиндустриального общества».

Вместе с тем существует и обратная точка зрения. Если одни считают, что институт образования выполняет миссию демократического общества, а именно - обеспечивает каждого равным доступом к общественным благам, есть исследователи, которые убеждены прямо в обратном: система образования закрепляет существующее неравенство, поддерживает статус-кво, выгодный людям, уже располагающим значительными ресурсами. Они также убеждены, что равенство шансов - очень относительное явление, поскольку имеются скрытые проблемы, препятствующие осуществлению демократических и гуманистических идеалов на практике в полной мере.

Существует несколько основных подходов к проблеме неравенства в образовании. Конфрликтный главным образом представлен классическим марксизмом, неомарксизмом, структурализмом и радикально-гуманистической теорией. Исследователи в рамках данного направления утверждают, что образование является элементом капиталистической системы, частью государственного механизма, а потому изначально направлено не на развитие, а на подавление личности и превращение человека в «винтик» гигантского аппарата-государства, подчиненного рыночным законам. Более того, образование в этом контексте только воспроизводит социальную дифференциацию, прививая ученикам ценности конформизма, приспособленчества и ориентации на оценку, а не на знания. Таком образом, система формирует навыки, необходимые рабочему классу в капиталистическом обществе, и не оставляет места для творческой деятельности личности [3].

Некоторые авторы склонны видеть в образовании поле борьбы различных статусных групп за укрепление положения и получение тех или иных благ: власти, престижа или дохода [4, с. 398]. Другие придерживаются мнения о том, что школы объективно отнимают у ребенка способность к самостоятельному мышлению, развивая зависимость от экспертных мнений и сторонних оценок [5, с. 12].

Такие причины образовательного неравенства относятся к внешним, социальным, проявлениям вопроса. Вместе с тем существуют и более неочевидные барьеры, блокирующие равный доступ людей к образованию, имеющие психологический или даже лингвистический контекст. Один из них рассмотрел британский социолог Б. Бернстейн в работе «Класс, коды и контроль». Ученый убежден, что дети из разных социальных слоев, даже обладая равными интеллектуальными способностями, имеют изначально неодинаковые условия доступа к получению образования, связанные с языковыми особенностями, которые формируются в среде данного класса.

Б. Бернстейн убежден, что классовая принадлежность детерминирует форму сознания, которая либо поможет ребенку при обучении, либо, наоборот, вызовет проблемы с восприятием информации, поскольку будет являться недостаточной для понимания школьного материала. Форма сознания, по Б. Бернстейну, выражается в первую очередь в речевом поведении или «языковом коде». Данное понятие определяется социологом как «культурная грамматика, индивидуализируемая классовым положением и полями практики» [6, с. 30]. Таким образом, языковой код, с одной стороны, выступает маркировкой социального положения классов, а с другой означает различия в структуре их мышления и восприятия информации, что накладывает отпечаток на успеваемость детей в школе.

Семьи из низших классов склонны упрощать предложения, не договаривать их, предполагая, что другая сторона уже осведомлена о необходимой информации. Например, мать в диалоге с сыном не будет объяснять, почему сладкое есть вредно, она просто запретит его есть императивным «нельзя». Помимо этого родители в таких семьях стремятся воздействовать на детей прямыми методами поощрения или наказания, чтобы быстрее приобщить их к нормам и ценностям своей среды, которые воспринимаются ими как сами собой разумеющиеся. Подобный код Б. Бернстейн называет «ограниченным».

Речь среднего и высшего классов, напротив, нацелена не на прямое описание, а на обобщение и анализ событий. Их представители уделяют немало внимания развитию речевых навыков, формированию проблемного видения событий и грамотного его выражения в речи. Высказывания конкретизируются, подаются развернуто, поэтому ребенок в данной среде учится управлять речью и обобщать мысли. В частности, мать семейства среднего или высокого класса скорее объяснит, почему она запрещает сладкое своему ребенку, приводя обоснованные аргументы. Такой код ученый назвал «развернутым».

Можно сказать, что речевые особенности представителей низших классов направлены на укрепление коллективной солидарности, в то время как речь представителей высших - на выражение собственных чувств, мыслей, эмоций. При этом нужно понимать, что Б. Бернстейн имеет в виду в первую очередь разницу в грамматике языковых кодов и, соответственно, разницу в мышлении представителей разных классов, а не интеллектуальное превосходство одних над другими. 
Этим объясняется различная успеваемость учеников высших и низших классов. Преподаватели в школе используют развернутый языковой код, что является неестественным для учеников из бедных семей. Их же код, с точки зрения учителей, считается «худшим», «бедным». Как следствие, те, кто изъясняется на «развернутом» языке, намного лучше приспосабливаются к академической среде, понимают и усваивают информацию, а потому считаются более любознательными и смышлеными.

Также стоит учитывать и отношение представителей рабочего класса к образованию. Люди, которые занимаются в основном только физическим трудом, чаще демонстрируют негативное отношение к обучению. Родители реже участвуют в школьной жизни, посещают родительские собрания и т. д. Дети перенимают эти установки и реже чувствуют заинтересованность в процессе обучения.

Таким образом, культурная среда имплицитно поддерживает ситуацию неравенства, создавая дополнительные препятствия за счет лингвистических особенностей и психологических установок. В связи с этим Б. Бернстейн выступает за введение компенсаторного обучения детей из рабочего класса.

Еще один пример подобной связи языка и успеваемости в школе мы можем найти у американских социологов К. Кидвелла и Д. Свифта [7]. Исследователи пишут, что при равном IQ дети из групп меньшинств менее успешно учатся в школе. Это происходит по ряду причин: в некоторых случаях это недостаточное владение литературным английским языком, а иногда роль играют иные модели воспитания, заложенные в первичной среде. Например, коренные американцы неодобрительно относятся к излишней разговорчивости детей, что сказывается на поведении последних в школьных классах. Дети из индейских семей приучены отвечать лишь тогда, когда к ним обращаются, что воспринимается учителями как отсутствие интереса к предмету или даже его незнание. Таким образом, теория Б. Бернстейна применима не только к выходцам из разных социальных слоев, но и к этническим меньшинствам.

Подобные исследования проводились и в СССР, где изучалась работа когнитивных структур коренных жителей Дальнего Востока (чукчей, эвенков), близких к ним народностей (якутов) и пришлого населения, мигрировавшего с европейской части страны. Оказалось, что у местных больше развито правополушарное (ассоциативное) мышление, а у пришлых - левополушарное (логическое). При этом различия в восприятии мира часто могли трактоваться пришлым населением как умственная отсталость, исследователи в этом контексте отмечают тенденцию к «гипердиагностике олигофрении» детей коренного населения [8, с. 58]. По мнению ученых, такое явление могло наблюдаться по причине недостаточной лексической и грамматической оформленности речи коренного народа, бедности ее наполнения по сравнению с таковой выходцев из европейской части СССР. В настоящее время труды по расовым или этнокультурным различиям тоже не редкость [9].

М. Янг утверждал, что в XXIв. установится действительное равенство в образовании благодаря введению IQ-тестов и отсутствию границ для социальной мобильности. Вместе с тем на практике мы видим, что повышение доступности образования не только не сокращает культурносоциальный разрыв, но порой и усугубляет его. Неравенство в образовании остается по причине неодинаковых стартовых условий (образования и статуса родителей, принадлежности к определенной этнической группе), следовательно, и неодинаковых когнитивных структур у представителей разных слоев общества.

Особенную актуальность теория Б. Бернстейна получила в аспекте ускоряющихся процессов глобализации. Массовые потоки миграции, смешение культур и этносов делают проблему всеобщего равенства очень острой, в том числе вопрос о равенстве в образовании. Система, ориентированная на «среднего» представителя класса или этноса, не учитывает уникальность каждой культуры, заставляя детей чувствовать свое несовершенство относительно стандартов, которым полностью может соответствовать только малая часть учащихся.

Правительства многих европейских государств, включая Россию, сделали направления демократизации, гуманизации и интернационализации основными в развитии образовательной системы. Приоритетом образовательной политики Великобритании с 1997 г. являются совершенствование человеческого капитала в условиях стремительных культурных изменений и возрастающей диверсификации общества, а также обеспечение полноценного развития каждого школьника, невзирая на культурный и социальный бэкграунд. Данный вектор политики означает отход от общепринятых моделей обучения в школе и выработку новых образовательных программ, так как классическое школьное образование заточено под культурные особенности среднего западного школьника.

Без сомнения, выводы английского социолога открывают лишь часть общей картины образовательной системы. Вместе с тем Б. Бернстейн задевает очень важную тему подводных камней в образовании, когнитивных различий учащихся, которые не всегда учитываются в школьной 
среде. На первый план выходит проблема коренного реформирования школьной системы для лучшего соответствия актуальным запросам современности. Таким образом, мы видим необходимость в освещении данного вопроса, а также в поиске новых перспектив и решений назревших проблем образования.

\section{Ссылки:}

1. Young M. The Rise of the Meritocracy 1870-2033. An Essay on Education and Equality. L., 1958.

2. Bell D. On meritocracy and equality. National Affairs // Public Interest. 1972. Vol. 29. P. 29-68.

3. Альтюссер Л. Идеология и идеологические аппараты государства (заметки для исследования) // Неприкосновенный запас. 2011. № 3 (77).

4. Бурдье П. Социальное пространство: поля и практики : пер. с фрр. / сост., общ. ред., пер. и послесл. Н.А. Шматко. СПб., 2005.

5. Иллич И. Освобождение от школ: пропорциональность и современный мир. М., 1976.

6. Бернстейн Б. Класс, коды и контроль. М., 2008.

7. Kidwell C.S., Swift D.W. Indian Education // American Education: A Sociological View. Boston, 1976.

8. Аршавский В.В. Особенности межполушарных взаимоотношений у коренного и пришлого населения Северо-Востока. В 2 ч. Магадан, 1985.

9. Downey D.B. Black/White Differences in School Performance: The Oppositional Culture Explanation // Annual Review of Sociology. 2008. Vol. 34, no. 1. P. 107-126 ; Farkas G. Quantitative Studies of Oppositional Culture // Minority Status, Oppositional Culture, and Schooling / ed. by J.U. Ogbu. N. Y., 2008. P. 312-348 ; Flashman J. Friend Effects and Racial Disparities in Academic Achievement // Sociological Science. 2014. Vol. 1. P. 260-276.

\section{References:}

Althusser, L 2011, 'Ideology and ideological state apparatuses (notes towards an investigation)', Neprikosnovennyy zapas, no. 3 (77), (in Russian).

Arshavsky, VV 1985, Peculiarities of interhemispheric relationships among the indigenous population and newcomers of the Northeast, in 2 parts, Magadan, (in Russian).

Bell, D 1972, 'On meritocracy and equality. National Affairs', Public Interest, vol. 29, pp. 29-68.

Bernstein, B 2008, Class, codes and control, Moscow, (in Russian).

Bourdieu, P \& Shmatko, NA (transl.) 2005, Social space: fields and practices, St. Petersburg, (in Russian).

Downey, DB 2008, 'Black/White Differences in School Performance: The Oppositional Culture Explanation', Annual Review of Sociology, vol. 34, no. 1, pp. 107-126. https://doi.org/10.1146/annurev.soc.34.040507.134635.

Farkas, G \& Ogbu, JU (ed.) 2008, 'Quantitative Studies of Oppositional Culture', Minority Status, Oppositional Culture, and Schooling, New York, pp. 312-348.

Flashman, J 2014, 'Friend Effects and Racial Disparities in Academic Achievement', Sociological Science, vol. 1, pp. 260

276. https://doi.org/10.15195/v1.a17.

Illich, I 1976, Deschooling society: balance and the modern world, Moscow, (in Russian).

Kidwell, CS \& Swift, DW 1976, 'Indian Education', American Education: A Sociological View, Boston.

Young, M 1958, The Rise of the Meritocracy 1870-2033. An Essay on Education and Equality, London. 